\title{
From the Executive Editor
}

\section{Learning from the Bristol Inquiry}

\author{
Edward Baker \\ Depa rtment of Paed iatric Card iology, Guy's Hospital, London, UK
}

$\mathrm{E}$ VENTS UNFOLDING ON THE WORLD STAGE HAVE brought a new uncertainty to our lives. This hew century is perhaps less inviting that we once thought. Certainly there will be change, but will it be for the better? Only time will tell. As we have highlighted before, the way we provide services for children and young people with diseases of their hearts is also bound to change. Not only will there be new and better treatments, but there will also be a new, developing, culture of partnership with these children and their families. We, the professionals providing care, will be held more and more accountable for what we do. This is change that is, at the same time, both worrying and exhilarating. We have a choice. Either we embrace this new culture of care, or we accept it grudgingly, as it is imposed upon us.

Here in the United Kingdom, the services provided for children with cardiac disease have been at the centre of the biggest upheaval in medical care seen in modern times. The biggest, and most expensive, costing approximately $\$ 20$ million, inquiry into health care published its report in July of this year. The inquiry centred on the care of children receiving complex cardiac surgery at the Bristol Royal Infirmary between 1984 and 1995. The main report, entitled "Learning from Bristol", stretches to 540 pages. It makes 198 recommendations. Many of these, if they are implemented, will make fundamental changes in the way paediatric cardiologists and cardiac surgeons work in the United Kingdom. ${ }^{1}$

So how good is the report? There had been many predictions that the report would be a witch-hunt, but it is not. It does not pull its punches, and strongly criticizes several individuals, but the

Correspondence to: Dr Edward Baker, Department of Paediatric Cardiology, Guy's Hospital, St Thomas Street, London SE1 9RT, UK. E-mail: edward.baker@ kcl.ac.uk tone of the report can be best judged from a short extract:

\begin{abstract}
"The story of the paediatric cardiac surgical service in Bristol is not an account of bad people. Nor is it an account of people who did not care, nor of people who wilfully harmed patients. It is an account of people who cared greatly about human suffering, and were dedicated and well-motivated. Sadly, some lacked insight and their behaviour was flawed. Many failed to communicate with each other, and to work together effectively for the interests of their patients. There was a lack of leadership, and of teamwork."
\end{abstract}

The statistical analysis commissioned by the inquiry shows that, between 1991 and 1995, between 30 and 35 more children died after open-heart surgery at Bristol than would be expected. There was certainly a problem, but it was not so much with individuals as with the culture of healthcare, the systems and structure in the British healthcare system, lack of clear standards, and lack of accountability. The chairman of the inquiry, Professor Ian Kennedy, said that he wrote the section on the report dealing with children's services with "some anger". Children with cardiac disease were not seen as a priority by the healthcare system. The anger he felt will be recognised by many professionals who have struggled to get a higher priority for these services over many years. It will also be shared by many parents, who feel they and their children have been let down by the system.

We commend this report to you. There is very little in it with which we would disagree. Much of the report covers specific events in Bristol, and many of the recommendations are about the British system. But there is also much that will interest our international readership, particularly the recommendations about the future of paediatric cardiac services. The report recommends that national standards should be set for all aspects of the care of children with cardiac disorders, including the minimum number of operations that should be carried out in any centre. 
Interestingly, it does not recommend a minimum volume itself, but does say that, in each year, each surgeon should undertake a minimum of 40 to 50 open-heart procedures on neonates and infants. It says that children with cardiac di sease must be cared for in a paediatric environment, not as an adjunct to an adult service. The report makes no recommendations about reducing the number of units overall, but does say that surgery for rare conditions, such as common arterial trunk, should be concentrated in a maximum of two units. There has been much discussion since the report was published about this last recommendation. Why common arterial trunk? Why not more complex conditions, such as tetralogy with pulmonary atresia and multiple systemic-topulmonary collateral arteries? Why not conditions known to have a particularly high risk, such as hypoplastic left heart? There will no doubt continue to be a heated debate. Regardless of this, the issue of concentrating the surgery for some conditions in a few centres has been firmly placed on the agenda.

Perhaps the main thrust of the recommendations of the report is directed at the analysis summarised above of what went wrong. The problem was with culture and systems. These must change, "The culture of the future must be a culture of safety and of quality; a culture of openness and accountability; a culture of public service; a culture in which collaborative teamwork is prized; and a culture of flexibility in which innovation can flourish in response to patients' needs."

Paediatric cardiac services in the United Kingdom are at a low ebb. Many feel demoralised by the constant drip feed of negative publicity in the last few years, and many feel threatened by the prospect of change. In contrast to this, a national audit of surgical outcomes has shown that results across the whole country are of a remarkably high standard, and that there is no difference in outcomes between any of the centres undertaking paediatric cardiac surgery. Indeed, there was no difference in the mortality rates between any of the individual surgeons. This, surely, is something to celebrate.

The cultural change taking place in medicine, and in our specialty particularly, both in the United Kingdom and in many other countries, is in our view welcome. It is an opportunity to provide care in better ways. The new culture will require new thinking. It will challenge our preconceptions, and will often make us feel uncomfortable, but we believe it will lead to better care, and better outcomes, for our patients.

\section{Reference}

1. Learning from Bristol: The Report of the Public Inquiry into children's heart surgery at the Bristol Royal Infirmary 19841995. www.bristol-inquiry.org.uk

\section{Acknowledgement to Reviewers}

In addition to members of the Editorial Board, we are greatly indebted to the following people, who have given freely of their time and expertise in evaluating the papers submitted to the Journal. It would be difficult to maintain our high standards without their continuing support, and we thank them all.

Hugh Allen, Columbus, $\mathrm{OH}$

David Anderson, London

Robert Arnold, Liverpool

Erle Austin, Louisville, $K Y$

Galit Bar-Mor, Petah-Tiqva

Maurice Beghetti, Geneva

Leonard Bleiden, Petah Tiqva

Philipp Bonhoeffer, London

Reiner Buchhorn, Göttingen

Frances Bu'Lock, Leicester

Michael Burch, Oxford

Mario Carminati, San Donato Milanese

Julene Carvalho, London

Michael Cheung, London

Gordon Cohen, London

Andrew Cook, London

Seamus Cullen, London

Luciano Daliento, Padova

Graham Derrick, London

Rami Dhillon, Birming ham

Abdul Duke, London

Martin Elliott, London

Perry Elliott, London

Nynke Elzenga, Groningen

Helena Gardiner, London

Freda Gardner, Bristol

Michael Gatzoulis, London

John Gibbs, Leed $s$

James Gnanapragasam, Southampton

Leslie Hamilton, New castle-upon-Ty ne

Joachim Hebe, Bremen

Willem Helbing, Rotterd am

Ziyad Hijazi, Chicago

Alison Hislop, London

Yen Ho, London

Alan Houston, Glasgow

Ian Huggon, Lond on

Stewart Hunter, Newcastle-upon-Ty ne

Harald Kaemmerer, München

Tom Karl, Philadelphia

Ed Ladusans, Liverpool

Robert Lewin, York

Alan Magee, London

Bruno Marino, Roma

Luc Mertens, Leuven

Cleonice Mota, Belo Horizonte

William Neches, Pittsburgh 
John O'Sullivan, Newcastle-upon-Ty ne Elfriede Pahl, Chicago

Ian Peart, Liverpool

Dan Penny, Melbourne

Marco Pozzi, Liverpool

Shakeel Qureshi, London

Rosemary Radley-Smith, Harefield

Reza Razavi, London

Eric Rosenthal, London

Babulal Sethia, London

Lara Shekerdemian, London

Savi Shrivastava, New Delhi

John Simpson, London

Zdenek Slavik, Harefield

Peter Smith, London

Keld Sorensen, Aarhus

David Southall, Stoke-on-Trent
Graham Stuart, Bristol

Oliver Stumper, Birmingham

Atsuko Suzuki, Tokyo

James Taylor, London

Robert Tulloh, London

Elizabeth Utens, Rotterd am

Maria Louisa Valente, Padova

Carin van Doorn, Leed $s$

Henri Verhaaren, Ghent

Elisabeth Villain, Paris

Michael Vogel, London

Götz Von Bernuth, Aachen

Gary Webb, Toronto

Hein Wellens, Maastricht

Christopher Wren, Newcastle

Robert Yates, London

James Zuberbuhler, Pittsburgh 